\title{
"Tentamos trabalhar, mas ninguém viu a maioria das propostas sendo efetivadas": impactos do Orçamento Participativo Digital de Volta Redonda entre 2017-2020
}

"We tried to work, but no one saw most of the proposals being carried out": impacts of the Digital Participatory Budget of Volta Redonda between 2017-2020

"Intentamos trabajar, pero nadie vio llevarse a cabo la mayoría de las propuestas": impactos del Presupuesto Participativo Digital de Volta Redonda entre 2017-2020

\section{Resumo}

O presente artigo tem por finalidade analisar as contribuições do Orçamento Participativo Digital de Volta Redonda (OPD-VR) no período de 2017-2020 para a efetividade da participação social no município de Volta Redonda nas suas relações locais e resolução de problemas públicos. Para tanto, partimos de referencial teórico acerca de participação, deliberação democrática e impactos do orçamento participativo digital. Metodologicamente, situamos pesquisa qualitativa com o apoio de aplicação de questionários e entrevista semiestruturada conduzida com membros relevantes que aturam diretamente no OPD-VR. A partir da Técnica de Triangulação criamos as categorias "Participação", "Representação", "Controle Social e Transparência" e "Distribuição de Recursos" para analisar e justificar o potencial analítico dos orçamentos participativos digitais em seu conceito, prática, alcance, disponibilidade e capacidade interventiva. Todavia, no caso de Volta Redonda, observamos que os mecanismos de participação digital que priorizam ações individuais, não oferecem espaços de deliberação coletiva e, de certa forma, diminuem a importância coletiva da participação.

Palavras-chave: Orçamento participativo digital; Políticas públicas; Volta redonda; Participação social.

\begin{abstract}
This article aims to analyze the contributions of the Volta Redonda Digital Participatory Budget (OPD-VR) in the period 2017-2020 for the effectiveness of social participation in the municipality of Volta Redonda in its local relations and resolution of public problems. To do so, we start from a theoretical framework about participation, democratic deliberation and impacts of the digital participatory budget. Methodologically, we placed a qualitative research with the support of questionnaires and semi-structured interviews conducted with relevant members who work directly in the OPD-VR. From the Triangulation Technique, we created the categories "Participation", "Representation", "Social Control and Transparency" and "Distribution of Resources" to analyze and justify the analytical potential of digital participatory budgets in their concept, practice, reach, availability and intervention capacity. However, in the case of Volta Redonda, we observe that the mechanisms of digital participation that prioritize individual actions, do not offer spaces for collective deliberation and, in a certain way, diminish the collective importance of participation.
\end{abstract}

Keywords: Digital participatory budget; Public policy; Volta redonda; Social participation.

\section{Resumen}

Este artículo tiene como objetivo analizar los aportes del Presupuesto Participativo Digital Volta Redonda (OPD-VR) en el período 2017-2020 para la efectividad de la participación social en el municipio de Volta Redonda en sus relaciones locales y resolución de problemas públicos. Para ello partimos de un marco teórico sobre participación, deliberación democrática e impactos del presupuesto participativo digital. Metodológicamente, colocamos una investigación cualitativa con el apoyo de cuestionarios y entrevistas semiestructuradas realizadas con miembros relevantes que trabajan directamente en el OPD-VR. A partir de la Técnica de Triangulación, creamos las categorías "Participación", "Representación", "Control y Transparencia Social" y "Distribución de Recursos" para analizar y justificar el potencial analítico de los presupuestos participativos digitales en su concepto, práctica, alcance, 
disponibilidad y capacidad de intervención. Sin embargo, en el caso de Volta Redonda, observamos que los mecanismos de participación digital que priorizan las acciones individuales, no ofrecen espacios de deliberación colectiva y, en cierto modo, disminuyen la importancia colectiva de la participación.

Palabras clave: Presupuesto participativo digital; Políticas públicas; Volta redonda; Participación, social.

\section{Introdução}

O presente artigo tem como tema a noção de política de participação democrática via instrumentos de orçamentos participativos. O problema de pesquisa se orienta em indagar quais as principais contribuições do Orçamento Participativo Digital de Volta Redonda (OPD-VR) no período de 2017-2020 para a efetividade da participação social no município de Volta Redonda nas suas relações locais e resolução de problemas públicos.

A cidade de Volta Redonda (RJ) é o lócus de análise desta construção participativa acerca da tomada de decisão governamental e de realocação de recursos públicos para fins de desenvolvimento territorial. A cidade possui um histórico de associativismo e mobilização popular e iniciou esta inovação democrática a partir da década de 1990, sendo implantado o Orçamento Participativo de Volta Redonda (OP-VR) em 1994. O OP-VR passou por uma reestruturação e reconfiguração metodológica em 2017 quando foi implantado o OPD-VR objetivando ampliar a participação para além das assembleias realizadas nos bairros.

Metodologicamente, desenvolvemos pesquisa qualitativa a partir da análise de Atas das Reuniões do Comitê do Orçamento Participativo (COP) e entrevistas com atores relevantes, a saber: Gestores públicos da Prefeitura Município de Volta redonda (PMVR); presidentes das associações; pessoas que ocuparam cargo comissionado na PMVR e participaram de alguma forma do OP-VR ou do OPD-VR, docentes da Universidade Federal Fluminense (UFF-VR) que trabalham com este tema sobre Orçamento Participativo, membros das sociedade civil do município de Volta Redonda.

Portanto, consideramos os instrumentos criados no contexto da democracia liberal e analisar em que alcance estes são capazes de dispor, fomentar, potencializar e institucionalizar um caráter deliberativo e participativo que tenha como base conceitual e prática o indivíduo e a coletividade sem um deslegitimar ou rebaixar o outro. Por este aspecto, justificamos o potencial analítico dos orçamentos participativos digitais em seu conceito, prática, alcance, disponibilidade e capacidade interventiva de modo a solucionar os problemas públicos apontados pelas pessoas nas formas discursivas de deliberação.

\section{Metodologia}

Utilizamos a pesquisa qualitativa, de acordo com Triviños (1987) e Minayo (2002). No sentido de ampliarmos nossa descrição, utilizamos a técnica da triangulação, segundo Triviños (1987). Ao utilizarmos a entrevista semiestruturada (questionário semiestruturado), a observação direta, documentos (Atas do COP, Regimento Interno do COP e demais documentos produzidos pelo OPVR), pudemos dirigir nosso interesse aos "Processos e Produtos", desde aos elementos produzidos pelo sujeito em seu meio; as percepções desse sujeito; os comportamentos e ações do sujeito, como também as forças e relações de produção (Triviños, 1987).

O período de 2017-2020 (parte) como delimitador do tempo de análise da pesquisa está relacionada a gestão atual da cidade de Volta Redonda e início do modelo híbrido do OP-VR. Já a amostragem de pessoas que farão parte do estudo serão conforme o pesquisador achar que são representativas (Gestores públicos da PMVR; presidentes das associações; pessoas que ocuparam cargo comissionado na PMVR e participaram de alguma forma do OP-VR ou do OPD-VR, docentes da Universidade Federal Fluminense(UFF-VR) que trabalham com este tema sobre Orçamento Participativo, membros das sociedade civil do município de Volta Redonda) de forma a demonstrar e comprovar as hipóteses do fenômeno estudado.

Cabe salientar que foram analisadas as Atas do Comitê do Orçamento Participativo de Volta Redonda (COP-VR) disponibilizadas no site do OP-VR (www.voltaredonda.rj.gov.br/op) do período de 18/01/2018 a 22/01/2020 (ano de 2018=17 
Atas; ano de 2019=13 atas e ano de $2020=01$ ata). Ressaltamos que as Atas do dia 19/02/2020 e 11/03/2020 não constam publicadas do site do OP-VR e após este período, foi justificado pela Administração Municipal que devido o início da pandemia da Covid-19 (Sars-Cov-2) as reuniões do COP-VR seriam paralisadas.

Por necessidade de coletar, complementar ou até mesmo, esclarecer as informações do OP-VR, fizemos várias solicitações a Prefeitura Municipal de Volta Redonda, através da Lei de Acesso à Informação (Lei n ${ }^{\circ} 2.527 / 2011$ ), pelo e-Sic da Prefeitura Municipal de Volta Redonda no período de 29/07/2019 a 19/05/2021 (2019=09 protocolos; 2020=12 protocolos e 2021=30 protocolos), ,como por exemplo, dados sobre o $\mathrm{n}^{\circ}$ de participantes/ano/OP-VR (presencial e digital); telas do processo de votação do OPD-VR; dados do IQVU; planilha com dados das demandas aprovadas e situação de cada obra e outras mais.

\section{Dimensões teóricas}

Entendendo que vivenciamos uma democracia liberal capitalista ao longo do século XXI, reportamos a Pateman (1992), que traz um entendimento de participação neste sistema capitalista pela base mercadológica, ou seja, uma competição ao qual nem todos estão aptos a participar. Nesse contexto, há um esvaziamento do sentido político do voto e do sistema, tendo como consequência uma desacreditação do sistema, bem como, uma desvalorização opinativa e, principalmente, faz com que o indivíduo venha a acreditar que o voto é o único momento de reconhecimento, fazendo com que o pensar de forma individual e não venham perceber sobre a importância coletiva da participação.

Em relação a este esvaziamento político, Offe (1984), que é um crítico no âmbito deste sistema, faz referência a essa lógica estruturante que traz o esvaziamento não da política, mas da cidadania, que passaria a ser algo a adquirir para aqueles que se mostrassem capazes e aptos e, não algo intrínseco as pessoas e como algo formador. Na verdade, este sentido mercadológico, faz com que as pessoas pensem como consumidoras, adquirir, consumir, status, abrindo mão do 'ser' por um 'ter', ou seja, num sistema democrático liberal, a participação passa a ser condicionada ao mecanismo de aquisição da cidadania.

Temos diante o seguinte contexto: uma representação não consegue tornar presentes os interesses coletivos que deveriam estar presentes, já que isto é algo inerente a ela. Então, pensadores têm sugerido uma participação democrática direta que proporcione uma alternativa de inserção dos cidadãos no poder público e, de certa forma, contrabalanceando as forças políticas, que ao longo dos anos tem excluídos aquelas pessoas dos benefícios da política, como também desencorajando a cidadania ativa (Pitkin, 2006).

Ao tratarmos sobre democracia participativa, precisamos entender como se dá esta participação no processo deliberativo democrático e como são percebidos os atores que irão participar. Neste sentido, há de se superar a ideia de apatia, desorganização e incapacidade dos cidadãos de intervir através do sistema político nos problemas que os concernem. Através de democracias mais participativas e, principalmente, deliberativas, a soberania popular pode insurgir seu poder comunicativo, relacionando-se com o administrativo, proporcionando uma forma mais robusta de prática democrática (Habermas, 1996; Sampaio; Maia; Marques, 2010).

A ideia deste princípio democrático é fugir das dimensões da racionalidade instrumental que orienta procedimentos em lógica de custo e benefício, além do utilitarismo latente da escolha das ações públicas. O propósito discursivo e deliberativo é o de colocar o agir da ação humana pelo contexto discursivo da esfera pública, ou seja, transformar o espaço público em aberto às capacidades discursivas e não pautadas pelo procedimentalismo da lógica burguesa formal da tomada de decisão pública por agentes representativos (Habermas, 2014).

Autores como Sampaio, Maia e Marques, (2010) têm destacado a importância da democracia deliberativa como uma área mais ativa na teoria contemporânea, ao incluir a discussão em atividades políticas que tratam de práticas cotidianas, bem 
como, o uso de ferramentais digitais que possibilitam a deliberação pública online. Entende-se que a internet permitiria um maior número de pessoas a deliberar, não existindo limitações de tempo e espaço, mas ao mesmo tempo destacam que existem fragilidades quanto à efetividade dessa deliberação, pois pode refletir posicionamentos particulares que não são confrontados, nem sentido, a uma perda de qualidade da discussão por escassez de troca de razões.

Diante desse contexto exposto, o conceito de participação envolve o interesse por participar que, em suma, “(...) tem se generalizado nos últimos anos, no Brasil e no mundo todo, (...)" (Bordenave, 1994, p. 7). A participação é inerente a natureza social do homem e algumas causas a favor da participação estão relacionadas ao descontentamento geral com as desigualdades econômicas-sociais, a marginalização do povo em assuntos que interessam a todos, mas são decididos por poucos (Bordenave, 1994).

Assim, para compreender o desenvolvimento e proposta reflexiva do Orçamento Participativo Digital de Volta Redonda, retiramos como principais elementos analíticos: 1) a ideia de deliberação discursiva, onde analisaremos as formas de construção dos problemas relativos ao desenvolvimento e suas soluções, assim como o contexto construtivo das soluções; 2) o sentido participativo, em que verificaremos as esferas participativa em caráter público e aberto, ampliado à capacidade de articulação de cidadania ativa e direta por diferentes mecanismos (internet ou físico); 3) a base democrática deliberativa e participativa, ou seja a conjugação dos itens anteriores cotejando as relações teóricas e práticas, das estruturas institucionais, procedimentais e de intervenção do estado que sejam reflexo desta base ampliada.

As demandas elencadas, debatidas e aprovadas no OP por aqueles que são afetados diretamente ou indiretamente, por falta ou desvantagem de acesso aos serviços prestados pelo Estado, de certa forma, minimizaria esta desvantagem ao longo do tempo e contribuiria para a universalização. Este processo poderia eliminar a associação da renda ao contexto participativo, bem como, reduziria a sistemática dos mais pobres serem os últimos a serem incorporados politicamente devido à renda. Porém, na trajetória do século XXI no Brasil, "a redução das distâncias no universo dos que têm direito a serviços essenciais está associada a um elemento comum: decisões sobre o desenho das políticas" (Arretche, 2015, p. 428). Não obstante, Brito, Santos, Dias e Santos (2020) advogam pelo impacto do orçamento público para com o exercício dos Direitos Fundamentais quando construído no sentido de uma política de Estado e que permita consolidar a democracia e o fortalecimento do controle social.

Neste sentido, infere-se que a definição das regras e suas políticas de um desenho institucional no OP podem reduzir os obstáculos aos mais pobres, uma vez que "as políticas e suas regras têm impacto crucial sobre a pobreza e a desigualdade". Porém não se deve "atribuir as mudanças em curso na estratificação social brasileira exclusivamente às políticas" (Arretche, 2015, p. 428). Ou seja, políticas que engendram mecanismos mais inclusivos e participativos são insuficientes em contexto que demanda outras ações políticas que permitam os contextos de participação social. Por exemplo: instituir sistemas de participação online, deve considerar se o território tem condições de acesso à internet, ou se o grupo social que é alvo da política, tem capacidade de acesso à mesma.

Sendo assim, ao abordamos a inclusão dos cidadãos nos mecanismos deliberativos, para Faria (2016) estamos diante das possíveis inabilidades dos grupos de terem voz e influência no debate público, que de certa forma, além de não possibilitarem que os assuntos que afetam suas vidas possam ser operacionalizados, também os constrangerá tanto na interação, como no diálogo público, somando a isso, "as desigualdades de riqueza, poder, conhecimento, formas e estilos de comunicação, bem como as formas como são estruturadas as questões, tendem a reforçá-las" (Faria, 2016, p. 210).

Ao mesmo tempo, que a comunicação pode trazer ganhos na conformação das preferências e na solução de conflitos num debate público, a inabilidade dos cidadãos pode comprometê-la (Faria, 2016). Além disso, outro fator importante é a significante capacidade de determinar quais as temáticas que terão predominância e visibilidade na agenda pública, bem como, quem são os interlocutores do debate, estas derivam do controle da informação. 
O capital influencia fortemente o fluxo de informações em todas as fases do processo político, que de certa forma, por diferentes grupos e interesses sociais têm a capacidade muito diferenciada de levar ao público suas percepções do mundo. Por outro lado, as novas tecnologias de informação seriam a promessa de reversão dessa situação, no entanto, contidas no modo de produção capitalista, corroboram para manutenção da reprodução do padrão de informação aos quais se deseja disseminar (Miguel, 2016). Ao mesmo tempo, as dinâmicas da tecnologia compreendem tentativas de se pautar novas formas de desenvolvimento social capazes de articular participação social em conteúdo colaborativo que se paute nas reivindicações daqueles diretamente afetados por determinada política pública - em suma, um processo de aproximar os formuladores de policymakers dos policytakers (Baptista, 2019).

Assim, nos orçamentos participativos digitais, que utilizam estas novas tecnologias de informação seriam suficientes para reverter a situação de quem detêm os fluxos e controle da informação? Em nosso objeto de estudo, as TICs são utilizadas numa das etapas, ao analisarmos esta nova tecnologia de informação neste mecanismo de participação social, pretendemos confirmar se estas ferramentas tecnológicas utilizadas no OP-VR, que foram criadas como o objetivo de ampliar a participação e melhorar o controle social, são capazes municiar os cidadãos de informações que servirão de base para o processo de discussão, deliberação e tomada de decisão.

O Orçamento Participativo (OP) é uma inovação democrática que articula entre a democracia representativa e democracia participativa (Santos \& Avritzer, 2002) e que oferece aos cidadãos a oportunidade de se envolverem diretamente nas questões públicas, bem como, participarem da tomada de decisão (Wampler, 2003). Segundo Paludo (2010) a importância do OP tem relação com a oportunidade de um espaço para debate e tomada de decisão dos investimentos em obras e serviços a serem realizados dentro dos limites orçamentários anuais, constituindo "a modalidade de gestão pública baseada na inserção da população na elaboração do orçamento público" (Bugarin; Vieira; Garcia, 2003, p. 153). Neste aspecto, Teixeira, Dias, Santos e Barros (2021) entendem que é preciso entender, pela lógica da eficiência e transparência a participação da população para com preparação, cumprimento e andamento do orçamento a fim de ajustar interesses locais e interesses de gestores públicos o que não está isento às tentativas clientelistas que podem ocorrer no meio do processo.

Seu principal benefício é a democratização da relação do Estado-sociedade com o fortalecimento da democracia, que rompe com os paradigmas de representação popular, resgatando a democracia direta participativa. Diante destes conceitos expostos, "o Orçamento Participativo (OP) é a experiência de participação local mais discutida no Brasil" e que teve início na cidade de Porto Alegre (RS), em 1989, que foi replicado em outras cidades (Avritzer, 2003, p. 13).

Para Avritzer (2003) o OP possui quatro características: cessão de soberania por aqueles que detêm o poder; reintrodução de elementos de participação local; princípio da auto-regulação soberana e tentativa de reversão das prioridades da distribuição de recursos públicos. Já Paes de Paula (2005) destaca que após o processo de redemocratização do país dos projetos políticos em desenvolvimento tem buscado construir um modelo de gestão pública com o intuito de atender às necessidades dos cidadãos brasileiros, de forma a ampliar a democracia no país, um com a vertente gerencial e outro na vertente societal. No caso, do OP este estaria incluído na vertente societal.

Essa nova forma de participação popular vem sendo experimentada recentemente, que é o uso das Tecnologias de Informação e Comunicação (TICs) nos OP. Podemos citar o Orçamento Digital da cidade de Belo Horizonte (MG) implantado em 2006, conforme trabalhos de Abreu (2012), Cunha, Coelho e Pozzebon (2014), Abreu e Pinho (2014). De fato, há uma mudança na sociedade advindas de novas tecnologias de informação e comunicação, sendo assim, a um debate sobre o quanto estas novas tecnologias podem criar possibilidades de ampliação da participação democrática dos cidadãos, sobretudo via práticas de participação na Internet (Abreu \& Pinho, 2014). Sendo assim, para que haja uma ruptura do velho sistema clientelista-patrimonialista o sentido de consolidação do OP há de mudar (Santos, 2002).

O Orçamento Participativo (OP) da cidade de Volta Redonda (RJ) teve início na década de 1990 e passou por uma 
reestruturação e também uma nova metodologia em 2017, a qual, segundo a SEPLAG-VR tinha como desafio resgatar a confiança dos munícipes, fazendo com que o controle do OP retornasse para as mãos da população, conforme nascera da década de 1990 (Seplag-VR, 2018).

Criou-se um Grupo de Trabalho, através do Decreto Municipal 14.351/2017, que tinha como objetivo estudar, junto às lideranças comunitárias, uma nova metodologia para o OP. Foi feito um mapeamento dos procedimentos adotados para a execução do OP no município e o intuito era a melhoria de cada parte do processo, tendo dois pontos principais, um em relação com a transparência e o outro quanto aos critérios de distribuição de recursos, que baseou-se da utilização do Índice de Qualidade de Vida Urbana (IQVU) (Seplag-VR, 2018).

Em 2017 foi realizado o I Fórum do OP, que tinha como objetivo principal apresentar a nova metodologia do OP, bem como eleger os representantes do Comitê do Orçamento Participativo (COP). O processo de reestruturação do OP contou com uma importante inovação no campo da governança digital, em 2017 foi implantado o Orçamento Participativo Digital (OPD), que tinha como propósito ampliar a participação popular para além das assembleias realizadas nos bairros, por meio da internet (Seplag-VR, 2018).

O Comitê do Orçamento Participativo (COP) de Volta Redonda, sancionado pela Portaria Municipal $\mathrm{n}^{\circ} 08$, de setembro de 2017 é uma instância de participação direta da sociedade civil com a Administração Pública, que entre as várias finalidades irá acompanhar o cumprimento das demandas do OP, fomentar a garantia dos direitos de participação social, cumprir o papel de mediador entre a sociedade civil e a gestão pública etc. A presidência da COP é exercida por um membro da SEPLAG-VR, os mandatos dos membros deste Comitê serão de 02 anos, permitida a recondução apenas uma vez (RI-COPVR, 2018).

Conforme Art. $1^{\circ}$, o formato do OP-VR é um modelo híbrido, com suas assembleias nos bairros/setores as quais por deliberações as demandas são elencadas, já a votação destas é unicamente por meio digital (RI-COP-VR, 2018). Para Wampler (2003) o OP como inovação é importante por dar ênfase na deliberação. Ao mesmo tempo, pode se configurar como uma medida de acompanhamento da própria capacidade da população em verificar a responsabilidade dos gestores públicos em dar celeridade às decisões tomadas.

Neste modelo híbrido do OP-VR, seu Ciclo Orçamentário inicia-se com a definição pelo poder executivo do valor que será destinado ao Orçamento Participativo; a próxima etapa são as assembleias nos bairros as quais são discutidas as demandas e elencadas as propostas que serão encaminhadas para a gestão municipal, que irá fazer a precificação das obras, além de avaliar sua viabilidade técnica, jurídica e orçamentária, resultando num 'filtro' das demandas; em seguida, de acordo com o Art. 36, I, II e $\S 1^{\circ}$, uma nova etapa é definição dos IQVU para a divisão dos recursos por setores, seguindo a uma lógica de inversão de prioridades, ou seja, aqueles setores com menor IQVU deverão receber o maior volume de recursos (RI-COPVR, 2018). Assim, como a seleção das propostas das demandas e distribuição dos recursos para as Unidades de Planejamento (UP), chegamos as três últimas etapas, que são o Fórum Participativo, a votação das demandas pelo OP Digital e a Audiência Pública da Lei Orçamentária Anual.

Ao analisarmos o Ciclo Orçamentário de um Orçamento Participativo, temos que nos ater a sua metodologia, já que pode variar, pois irá depender da forma de orçamento participativo (digital, semidigital, presencial) que será implantado, como também, o desenho institucional. Para Avritzer (2003), a influência do desenho das instituições pode determinar a capacidade das atitudes dos atores sociais e ao mesmo tempo criar condições para o desenvolvimento de organizações cívicas. Neste sentido, Wampler (2003) acrescenta que as regras criadas pelo desenho institucional irão conformar as estratégias dos atores políticos, bem como os resultados políticos e de políticas públicas.

Diante deste contexto, o desenho institucional irá delinear a metodologia do ciclo orçamentário, de modo que ele possa ter ou não, em suas etapas, mecanismos de participação política e deliberação pública online e off-line. A título 
exemplificativo, podemos citar dois institutos participativos: Orçamento Participativo Digital de Belo Horizonte-2006 (OPDBH) e o Orçamento Participativo de Recife-2007 (OPR), ambos utilizam as TICs em alguma etapa do ciclo (semidigitais) ou são totalmente digitais, com o objetivo de promover a ampliação da participação e inserir novos atores ou segmentos (Ferreira, 2014; Nabuco; Macedo; Ferreira, 2009).

\section{Resultados e Discussão}

No que se trata a avaliação do OP-VR, consideramos para análise as categorias, subcategoria, âmbito e elementos de observação. A partir da nossa fundamentação teórica e da coleta de dados, pudemos depreender que determinadas categorias subsidiavam os estudos e apontamentos relacionados ao Orçamento Participativo. A partir disso, escolhemos e sintetizamos algumas categorias relacionadas ao OP, que também pudessem relacionar aos elementos, aspectos e ideia do propósito inicial que tinha a reestruturação do OP-VR e isso também era relacionado ao OPD-VR, conforme a seguir: Participação política (OPD: propósito de ampliar a participação para além das assembleias realizadas nos bairros e disponibilizar uma ferramenta digital que se direciona àqueles que não dispõem de tempo para os encontros presenciais e que exercem forte participação pela internet (SEPLAG-VR, 2018); Representação (OPD: Potencial de ruptura de uma cultura anterior baseada no clientelismo, particularismo e patrimonialismo); Controle Social e Transparência (OPD: melhoria de cada parte do processo, aumentando o controle social e transparência) e Distribuição de Recursos (OPD: novos critérios de distribuição de recursos - IQVU - lógica de inversão de prioridades). Abaixo os Quadros 1 a 4, a seguir: 
Research, Society and Development, v. 10, n. 14, e543101422491, 2021

(CC BY 4.0) | ISSN 2525-3409 | DOI: http://dx.doi.org/10.33448/rsd-v10i14.22491

Quadro 1. Categoria 'Participação'.

\begin{tabular}{|c|c|c|c|}
\hline Categoria & Subcategoria & Âmbito & Elementos de observação \\
\hline \multirow{23}{*}{ Participação } & \multirow{11}{*}{$\begin{array}{c}\text { Participação } \\
\text { Política }\end{array}$} & \multirow{5}{*}{$\begin{array}{c}\text { Desenho } \\
\text { institucional }\end{array}$} & Reestruturação da metodologia. \\
\hline & & & Presidência do COP \\
\hline & & & Sugestão das pautas no COP \\
\hline & & & Discussão e deliberação no COP \\
\hline & & & Vocalização em espaços participativos \\
\hline & & \multirow{5}{*}{$\begin{array}{l}\text { Escola de } \\
\text { cidadania }\end{array}$} & Construção coletiva \\
\hline & & & Aprendizado político e consciência cidadã \\
\hline & & & Estrutura de incentivos e motivação em participar \\
\hline & & & Credibilidade \\
\hline & & & Tempo de vida do OP \\
\hline & & $\begin{array}{l}\text { Correlação de } \\
\text { forças }\end{array}$ & Exercício do poder \\
\hline & \multirow{3}{*}{ Deliberação } & \multirow{3}{*}{$\begin{array}{c}\text { Espaço } \\
\text { deliberativo }\end{array}$} & Quórum plenário COP \\
\hline & & & Temas discutidos da deliberação pública \\
\hline & & & Mecanismos de discussão e deliberação online \\
\hline & \multirow{9}{*}{ TICs OP } & \multirow[t]{4}{*}{ Potencial } & Ampliar a participação e a fiscalização \\
\hline & & & Potencial transformador \\
\hline & & & Potencial quanto ao alcance \\
\hline & & & Custo da participação \\
\hline & & \multirow[t]{3}{*}{ Limitações } & $\begin{array}{c}\text { Exclusão digital (quanto ao acesso, aspectos } \\
\text { geográficos e cognitivos) }\end{array}$ \\
\hline & & & Formas de mitigação \\
\hline & & & Resistências \\
\hline & & Críticas & Modelo híbrido inicial \\
\hline & & OPD-VR & Estímulo à participação \\
\hline
\end{tabular}

Fonte: Elaborado pelos autores. 
Quadro 2. Categoria 'Representação'.

\begin{tabular}{|c|c|c|c|}
\hline Categoria & Subcategoria & Âmbito & Elementos de observação \\
\hline \multirow{11}{*}{ Representação } & \multirow{6}{*}{$\begin{array}{l}\text { Complementaridade } \\
\text { entre participação e } \\
\text { representação }\end{array}$} & \multirow{3}{*}{ COP-VR } & Paridade \\
\hline & & & Controle de frequência \\
\hline & & & Emendas impositivas \\
\hline & & \multirow{3}{*}{ Dualidade de poder } & Forças políticas \\
\hline & & & Relações de poder \\
\hline & & & Mobilização \\
\hline & \multirow{5}{*}{$\begin{array}{c}\text { Mandato, autorização e } \\
\text { independência }\end{array}$} & \multirow{5}{*}{ Representação COP } & Concepções e posicionamento \\
\hline & & & Retorno as bases \\
\hline & & & Relações horizontais e verticais \\
\hline & & & Pluralidade \\
\hline & & & Controle efetivo da população \\
\hline
\end{tabular}

Fonte: Elaborado pelos autores.

Quadro 3. Categoria 'Controle Social e Transparência'.

\begin{tabular}{|c|c|c|}
\hline Categoria & Subcategoria & Elementos de observação \\
\hline \multirow{4}{*}{$\begin{array}{c}\text { Controle Social e } \\
\text { Transparência }\end{array}$} & \multirow{3}{*}{ Controle social } & Fonte da informação \\
\cline { 3 - 3 } & & Capacitação \\
\cline { 3 - 3 } & & Multiplicação do conhecimento \\
\cline { 3 - 3 } & \multirow{2}{*}{ Transparência } & Disseminação das informações e publicidade \\
\cline { 3 - 3 } & & Uso das TICs \\
\cline { 3 - 3 } & & Captação externa \\
\hline
\end{tabular}

Fonte: Elaborado pelos autores.

Quadro 4. Categoria 'Distribuição de Recursos'.

\begin{tabular}{|c|c|c|}
\hline Categoria & Subcategoria & Elementos de observação \\
\hline \multirow{3}{*}{$\begin{array}{c}\text { Distribuição de } \\
\text { Recursos }\end{array}$} & Capacidade de investimentos & Capacidade financeira \\
\cline { 2 - 3 } & Capacidade de execução das obras & Implementação de demandas \\
\cline { 2 - 3 } & Indicador de distribuição de recursos - IQVU & Delimitados pelo OP-VR \\
\hline
\end{tabular}

Fonte: Elaborado pelos autores.

O processo de reestruturação do OP-VR, implantou o OPD-VR, cuja a "ação teve como propósito ampliar a participação popular para além das assembleias realizadas nos bairros (...)" (SEPLAG-VR, 2018, p. 13), então quanto ao alcance da iniciativa tanto da reestruturação do OP-VR, quanto do OP Digital, seus resultados e impactos, demonstram que 
houve um significativo aumento do número de participações no período de 2017-2018 tanto na forma presencial (assembleias nos bairros), como também na forma digital (voto), bem como um aumento de associações de moradores interessadas em discutir o orçamento público (SEPLAG-VR, 2018), conforme Tabela 1.

Tabela 1. OP-VR - Ano/Participações

\begin{tabular}{c|c|c|c}
\hline Ano & OP-Presencial & OP- Digital & Bairros Participantes \\
\hline 2017 & 1629 & 859 & 47 \\
\hline 2018 & 2031 & 1838 & 77 \\
\hline Variação \% & 24,8 & 113,97 & 63,8 \\
\hline
\end{tabular}

Fonte: Elaborado pelo autor ${ }^{1}$.

Conforme trechos das falas dos Entrevistados I e IV, a implantação do OPD-VR, além do propósito de ampliar a participação, tinha o propósito de revigorar um processo que vinha desgastado, fragilizado, sendo assim, com a possibilidade de trazer novos atores ao processo, dar um certo empoderamento aos participantes, mas não eliminar a participação presencial (Luciano \& Baptista, 2020). Observe os trechos a seguir:

O nosso esforço na época da implantação foi fazer com que o processo, que já vinha bastante desgastado na época, pudesse ter uma, ser revigorado, literalmente tá, você teve um boom da participação lá traz, nos governos populares em especial, isso foi decaindo ao longo dos anos, de maneira que começou a enfraquecer o OP, (...). (...), então você tinha uma metodologia bastante amarrada no começo e ao final do processo presencial, puramente presencial, a coisa estava bem mais fragilizada, então uma das movimentações, das intenções do OP Digital foi justamente revigorar o processo, trazendo inclusive mais atores para se inserir nessa dinâmica (Entrevistado I, Seplag).

E eu vejo a participação virtual como forma de ampliar a participação, muitos críticos colocam a participação virtual vai eliminar a participação presencial, olham como uma certa dicotomia em relação as duas questões, não é isso, a ideia da participação virtual é justamente para a gente ampliar, é claro que há os seus riscos, as suas questões, como os gestores ele podem identificar participação virtual, eliminando totalmente, realmente a participação presencial, o que eu não concordo, acredito que a participação virtual ela deve ampliar, nesse ampliar $e$, aí considerando essa questão de dificuldade de acesso, é que você deve também prover de mecanismos, estruturas suficientes para que a participação virtual ela ocorra, (...) (Entrevistado IV, Seplag).

Vale destacar, que foi criada uma Comissão para criação do Regimento Interno do COP, composta por membros da gestão pública e representantes da sociedade civil e conforme registro da Ata do dia 25/01/2018, durante uma reunião desta comissão, tendo como pauta a criação e revisão do Regimento Interno do Comitê Orçamento Participativo de Volta Redonda, um membro e representante de um Movimento Social de Volta Redonda sugeriu que " após o primeiro mandato do COP abrisse para a plenária discutir se seria viável eleições para a presidência do COP, abrindo a oportunidade para que alguém da sociedade civil, membro do COP, assumisse este cargo", com isso a comissão, na mesma reunião, elaborou o texto do questionamento do membro representante, entretanto, propôs que "o COP irá deliberar este tema", fato que não vimos consolidar ao analisarmos as Atas do COP publicadas no site do OP-VR, como também não foi efetivado, já que conforme já citado Art. 17 do RI-COP-VR (2018), o cargo de presidente do COP está nas mãos da representação da SEPLAG-VR.

Durante o processo de reestruturação, a partir de 2017 com o OP-VR, ocorreram entendimentos diferentes dos atores sociais quanto a uma nova metodologia e o desenho institucional em relação ao resultado que eles almejam, já que conforme entendimento de Lüchmann (2014, p.187), "os desenhos institucionais são resultados de diversos fatores, variando de acordo

\footnotetext{
${ }^{1}$ A partir de dados da SEPLAG-VR (2018) e informação solicitada e recebida via e-SIC de Volta Redonda através do Protocolo nº75/2019, solicitada em 16/09/2019 e respondida em 28/08/2019 pela Administração Geral.
} 
com os objetivos, a composição dos atores sociais e governamentais, as correlações de forças e de interesses".

A partir da afirmativa acima, pudemos depreender nas falas de alguns entrevistados como eles percebiam o desenho institucional e a nova metodologia implantada, como a do Entrevistado XI que aponta a dificuldade de entendimento e aceitação por parte dos representantes das associações de moradores em relação a metodologia, conforme trecho a seguir:

(...). Em 2017 a divulgação e a metodologia para aprovação das demandas não foram bem definidas e interpretadas, com isso houve muitos desencontros e insatisfações, tanto da comunidade quanto dos agentes públicos. Lembro da dificuldade de entendermos a metodologia e da aceitação por parte dos representantes das associações de moradores (Entrevistado XI, Sociedade Civil).

Para Vaz (2011), apoiando-se nas perspectivas principalmente de Pateman (1992), uma ampliação da participação política direta dos cidadãos levaria ao aprendizado democrático e consequentemente levaria ao aprofundamento democrático. Acrescentando, Lavalle (2011) destaca que a principal função da participação na teoria democrática participativa sob a perspectiva pateniana é a educativa, seus efeitos pedagógicos, capazes de deflagrar círculos virtuosos em que a participação gera mais participação, ou seja, o caráter educativo da participação relacionada a potencializar ações individuais na ordem coletiva.

Correspondentemente, Marquetti e Campos (2008) destacam que o aprendizado que decorre da participação no processo político vai muito além da agregação de preferências, definidas ao processo, para a tomada de decisões. Com isso, pudemos depreender o sentido dessa afirmativa no trecho da fala do Entrevistado $\mathrm{X}$ ao ser perguntado como foi sua experiência no OP-VR no período de 2017 a 2020:

(...). Então para mim, aprendi muito, momento de muito aprendizado, principalmente sobre o orçamento e também foi mais um ambiente onde eu pude exercer o direito à cidadania e, bem como, ali ser ouvido, a expressar minha opinião, assim como todos ali, fazendo suas críticas com liberdade, fazendo as suas críticas sem censura, levando suas ponderações e exposições de opiniões diversas e ali criando um ambiente de discussão das mais diversas visões e opiniões, principalmente de ideias e soluções para conseguir construir uma alternativa melhor. Então, eu sempre falava que o Orçamento Participativo é a busca de construir uma cidade mais justa e a forma de construir uma cidade mais inclusiva (Entrevistado X, Movimento Social).

Considerando os elementos sócio-históricos dos atores sociais, autores destacam outro obstáculo à participação nas IPs, que seriam as desigualdades, como as materiais que se manifestam em capacidade assimétrica de influência política (Miguel,2017), pela seletividade assimétrica, tanto ao acesso quanto à participação, um extremo oposto do ideal participacionista (Silva, 2011).

Em relação à desigualdade de acesso ao ambiente digital e a participação virtual, pudemos inferir do trecho da fala do Entrevistado IX, que aqueles cidadãos que residem em locais periféricos convivem com a dificuldade de acessar uma ferramenta, como também a informação com aquela ferramenta poderia trazer uma demanda para seu bairro, conforme abaixo:

Tudo era novidade, posso falar pelas associações de moradores, pois tem locais que eram difíceis acessar a internet nas periferias da cidade. Às vezes o local não permitia acesso por falta de estrutura dos sinais não chegavam. Mas a ideia em si era boa, pois não ficava apenas nas assembleias que por sua vez, muitos não participam e nem sabem do que se trata Orçamento Participativo de sua cidade e como é feita para elencar as obras de prioridade em seu bairro (Entrevistado IX, Setor 6).

Pudemos verificar que reestruturação do OP-VR ocorrida em 2017 e que implantou a ferramenta digital, o OPD-VR, não introduziu mecanismos para discussão e deliberação online. Logo, conforme destaca Ferreira (2012, p.194) “(...) a ausência das arenas de interação, debate e negociação online reduz, a nosso ver, a qualidade do processo deliberativo, pois 
ainda que possa haver maior agregação de indivíduos, não há a deliberação". Aliás, a falta de mecanismos de deliberação online, até em um espaço institucionalizado como o COP, foi ponto de crítica do Entrevistado X, como também, no entender do Entrevistado II, como uma possibilidade de acontecer no COP durante a pandemia da Covid-19 (Sars-Cov-2), já que as reuniões presenciais do COP paralisaram desde o início da pandemia, conforme trechos a seguir:

Bem, sobre a questão de deliberação online sobre o orçamento, isso valeria mais para o modelo pandêmico, que na minha visão, Conselho não pode parar, conselho de participação social e, principalmente, que tem responsabilidade de controle social não pode parar. [...]. E pelo que sei até então, desde o período pandêmico não tenho ouvido reuniões online sobre deliberar sobre o Orçamento Participativo, pelo menos não no Comitê. Ele parou desde 2020, desde que começou a pandemia, isso é muito triste e não tem motivo, não tem justificativa para que não ocorra. Isso tem que ocorrer sim, tem que protagonizar isso, talvez fazer uma nova eleição para o Comitê e tocar para frente, porque algo que começou muito avançado de participação, controle social, deliberação com a sociedade, gestão social, não deveria ter paralisado. Só porque tem que a reunião só pode ocorrer agora de forma online, isso não existe, mas infelizmente é o que tem ocorrido (Entrevistado X, Movimento Social).

Considerando os impactos relacionados ao COVID19 no que se refere a reuniões presenciais com grande contingente de pessoas podemos considerar que a ampliação de metodologias que privilegiem o ambiente virtual será cada vez mais comum e podem de fato ampliar o número de atingidos por projetos relacionados a área orçamentária (Entrevistado II, Seplag).

A questão da exclusão digital foi debatida no OP-VR, como também as possibilidades de diminuir ou aproximar os excluídos, mas há menção quanto ao processo do OP-VR e consequentemente o OPD-VR proporcionar uma maior abrangência da participação, os obstáculos como a exclusão digital, precisam ser superados de forma gradual, conforme trechos a seguir:

A questão da exclusão digital, a gente chegou a debater, mas no cenário brasileiro hoje e no cenário mundial, de maneira geral, outras experiências dessa natureza, isso acaba não sendo um elemento central, tá Evandro, porque você tem hoje, por mais que você tem o acesso à internet não universalizado, pelo computador por exemplo, você tem a questão do Smartphone como elemento quase universalizado no cenário brasileiro, mais de $95 \%$ dos brasileiros possuem aparelho e tudo mais (...) (Entrevistado I, Seplag, 2021).

Então, esta questão da exclusão é bem complicada, porque ao mesmo tempo que você, que ele é excluído da participação presencial, na virtual ele continua sendo excluído, então para que você possa diminuir isso ou aproximar ainda mais esse jovem ou esse indivíduo que está tendo a exclusão digital, ele tem a possibilidade de participar [...] é também uma forma de você facilitar o acesso, então é muito uma questão de acessibilidade, de usabilidade também dos portais eletrônicos e isso tem que estar alinhado com a etapa digital de qualquer instrumento de participação (Entrevistado IV, Seplag, 2021).

Quanto ao modelo hibrido inicial (pessoas poderiam apresentar também as demandas de forma online) do OP-VR, depreende-se que não agradou alguns membros. Inclusive, levanta pontos que implicam contextos de justiça (Baptista, 2020), ou seja, elementos que circunscrevem não apenas recursos em disputa, mas conceitos e perspectivas de delimitam padrões e formas de distribuição dos mesmos no jogo dos interesses. Tal dinâmica é nítida conforme consta no trecho da Ata do COP e da fala do Entrevistado XI:

M. F. M. P (Setor 5) informou que no último OP Digital houve obras de um bairro que intervia em outro bairro; solicitou que a Gestão disponibilize as informações necessárias para evitar essa falha de que as associações não enviem obras que afetem outros bairros, consequentemente usando verba destinada a este outro bairro, o que causaria injustiça; (...) (Ata do dia 28/02/18).

Nossa população já estava acostumada a participar com demandas a serem atendidas pelo município. Fomos uns dos primeiros municípios a permitir essa participação popular nas ações do governo. Esse OPD não incentivou novos participantes, o que ocorreu, no meu entendimento, foi grupos de interesses comuns propondo intervenções que não eram o que a comunidade local desejava (Entrevistado XI, Sociedade Civil). 
Porém, há aqueles que entendem que o modelo híbrido ampliou as possibilidades além das assembleias, como o Entrevistado IX:

As obras na forma antiga muitas pessoas ficaram de fora sendo apenas em assembleias, mas quando se abriu também online, se ampliou bastante nas votações e não ficando apenas as associações decidindo por si só as obras que deveriam também os moradores se pronunciar (Entrevistado IX, Setor 6).

Já quanto à qualidade da representação nas experiências de democracia participativa, Marquetti e Campos (2008, p.21) veem como fundamental a questão de quais os setores que participam desse processo e como tais setores são "(...) capazes de influenciar a agenda política e de se fazer ouvir e representar pelas instituições políticas existentes", ou seja, se os setores que efetivamente participem forem aqueles grupos que “(...) tradicionalmente beneficiados pelo poder econômico e político, os processos irão reproduzir as condições de desigualdade existentes". Vale destacar, que para o Entrevistado VIII (SMI), em Volta Redonda a sociedade civil já era altamente participativa, iniciada em gestões passadas, por uma liberdade que o antigo gestor dava às associações e aos moradores. A diferença, em 2017, que a classe média alta, participou mais ativamente.

Quanto ao quantitativo total da representação nas reuniões do COP, consta um maior número totais de representação da sociedade civil (347), que se dividirmos pelo total de reuniões (29), teremos uma valor aproximado de 12 membros da sociedade civil por reunião, que é o número de representantes titulares provindos das Associações de Moradores, conforme consta no RI-COP-VR (Art. $3^{\circ}$, I), no entanto, além dos suplentes (12) das Associações de Moradores, também este Comitê tem 02 representantes titulares e 02 suplentes provindos tanto de Movimentos Sociais e de Conselhos Municipais (RI-COPVR, Art. $3^{\circ}$, II e III), já a representação da Gestão Pública Municipal totaliza 26 representantes, entre titulares e suplentes (RICOP-VR, Art. $3^{\circ}$, IV).

Mas o que estes números nos mostram, primeiro, o COP é um espaço aberto para participação da população, conforme consta no RI-COP-VR “(...) é uma instância de participação direta da sociedade, tendo por finalidade propor e debater temáticas relacionadas à sua finalidade, (...)" (Art. $1^{\circ}$ ), então podemos inferir que neste espaço aberto de participação e deliberação, a participação maior é dos representantes dos setores. Mesmo assim, quando analisamos as Atas do COP, pudemos verificar que existe uma predominância nas proposições por parte dos Membros da Diretoria Executiva do COP e de membros da Administração Municipal.

A partir de um trecho das falas do Entrevistado IV, percebe-se que ele teve um entendimento muito próximo do Entrevistado I quanto aos presidentes de associações de moradores ligados a vereadores, que segundo ele, com a reestruturação do OP-VR, algumas lideranças tiveram interesse no processo, outros continuaram com o formato que ligavam eles diretamente ao poder legislativo, entendendo que “(...) o processo era muito complexo e que era mais fácil pedir uma obra para o vereador, que ele seria atendido. Então, este sentimento ainda pairou, esse sentimento mais clientelista mesmo (...)" (SEPLAG, 2021).

Ainda sobre esse contexto, o Entrevistado IV (SEPLAG, 2021) afirma que em alguns bairros as quais as lideranças não aderiram ao OP-VR, entendiam que não valia a pena participar, optando em manter o formato que era pautado nas relações com o legislativo, então como o presidente daquela associação não participava, não fazia assembleia, consequentemente não tinham propostas, deixava aquele bairro descoberto, com isso, a Administração Municipal lançou editais para escolha de um mobilizador social, uma liderança comunitária ou pessoa que quisesse se candidatar para debater as obras do OP, essa foi uma das soluções encontradas pela gestão para tentar vencer o desafio de atender bairros descobertos. Dessa forma, trazendo como exemplo as associações clientelistas, conforme Abers (1998: 49), essas são "caracterizadas por seu caráter fechado e nãoparticipativo. (...)obtêm benefícios através de uma relação exclusiva entre os líderes comunitários e seus chefes políticos".

Em relação à pluralidade, para o Entrevistado X (Movimento Social) há anos o OP-VR construía as propostas através 
de alguns presidentes das associações e a prefeitura a portas fechadas, não tinha diversidade alguma, então ele viu com a reestruturação do OP-VR e a implantação do OPD-VR uma possibilidade de criar um ambiente favorável ao pluralismo, dinamismo de ideias e participação, conforme trecho:

Agora com o novo OP, principalmente o Digital, você vê uma diversidade de pessoas, você vê um pluralismo de ideias, por causa de que você está elegendo agora vários representantes de vários bairros, também você inclui aí os movimentos sociais que foram cruciais para trazer uma visão mais ampliada (...) (Entrevistado X, Movimento Social).

Quanto à questão do controle social, os membros representantes da Administração Municipal (PMVR) destacaram em várias Atas do COP que a fiscalização dos projetos e obras, que o controle dos processos e sobre ter esclarecimentos de tudo isso perante aos representantes do Poder Público, não deveria apenas ficar com a Administração Pública, mas essa fiscalização também deveria vir da sociedade civil, ressaltando que o OP não é apenas composto de participação social, mas também de controle social por parte da população. O Entrevistado VIII e I, reforçam a questão da relação entre envolvimento na participação e controle social "Para existir um controle social as pessoas precisariam estar mais envolvidas e querendo realmente participar e saber das ações públicas” (Entrevistado VIII, Seplag, 2021) e o Entrevistado I afirma:

A capacitação que a gente oferecia, ela acabava ajudando muito nesse processo de entendimento das relações público e privado e tudo mais, ela tinha o potencial e possibilidade de aumentar o controle social porque ela não se prendia só na ferramenta, você tinha ali a possibilidade de ampliar a visão para outras instâncias do poder público, mas ao mesmo tempo, a coparticipação foi muito limitada em termos de adesão das pessoas, eu acho que o potencial foi bem estreito (Entrevistado I, Seplag).

A capacidade financeira e, consequentemente, a distribuição de recursos são fatores fundamentais, centrais e até vitais para o sucesso de políticas participativas e redistributivas (Marquetti \& Campos, 2008; Wampler, 2003). Na mesma linha de raciocínio, Santos (2002) indica o vínculo da participação e distribuição de recursos como virtude ou talvez limitação do OP. Já Wampler (2003) traz uma relação entre participação e repasse de recursos para o OP, segundo este autor, quando a participação dos cidadãos é alta, há uma pressão sobre a administração em repassar recursos para o OP, como também a transparência e/ou controle social serão mais facilmente realizados, já que existirão mais pessoas interessadas nos resultados. Conforme afirmativas dos Entrevistados III, II e IV abaixo:

Foram expressas nas reuniões. Se falava dos vídeos que o prefeito fazia sobre a calamidade financeira que o município enfrentava (...) (Entrevistado III, Seplag, 2021).

A SEPLAG em conjunto com o gabinete do Prefeito apresentou aos interessados, desde as primeiras reuniões de aproximação, que a capacidade de investimento da PMVR era extremamente limitada (...), que durante toda a gestão foi extremamente limitada (Entrevistado II, Seplag).

Essa parte da capacidade administrativa e financeira a gente sempre assim, trazia uma devolutiva para os representantes, uma coisa que a gente sempre fazia. (...). Acho que faltou realmente uma aproximação mais forte do poder executivo em relação ao OP, (...) quando a gente teve uma crise financeira no ano de 2018, a gente né, explicou para o COP, em virtude dos precatórios judiciais, da dívida acumulada pela prefeitura, então tudo foi muito transparente (Entrevistado IV, Seplag).

No âmbito do processo de implementação das demandas e priorização dentro do âmbito municipal, um membro J. de M (SMS) explanou numa das Atas do COP que:

(...) as obras do orçamento participativo precisam ser prioritárias no governo e que para os processos administrativos ganharem uma maior celeridade recomendou que se coloque ao início dos processos das obras uma etiqueta dizendo 
que é obra do OP para que haja uma atenção maior nestes (Ata Do Dia 09/10/19).

Já ao perguntarmos aos entrevistados sobre o que ele viu materializar-se a partir da reestruturação do OP-VR em 2017, o Entrevistado X respondeu:

(...). Isso tentamos trabalhar, mas é claro, que eu não vi isso materializar, assim como setores também que levavam propostas para os seus bairros não viram materializar grande parte das obras. Elas foram aprovadas e tal, foram enviadas para serem colocadas no orçamento, mas ninguém viu a maioria das propostas sendo efetivadas, (...). (...) grande maioria esmagadora não tinha sido aprovada depois de dois anos de aprovação da primeira rodada de propostas. Então isso, claro, vai trazer enfraquecimento do orçamento, porque as pessoas participam, gastam tempo, energia, recursos, mas não veem materializando aquilo que ela tanto demanda e ela também passa pela pressão de seus bairros, os moradores que participaram das assembleias e tal e associação teve que fazer movimentação, mas não viu aquilo se concretizar e cobra seu presidente da associação, cobra sua associação e a associação acaba cobrando o governo, mas ele não acabava vendo mudança, não via as obras nem sendo iniciadas, então isso acaba gerando uma desconfiança, um desinteresse, uma desilusão né, de não ver essa coisas acontecendo (Entrevistado X, Movimento Social).

E o Entrevistado XII acrescenta "as pessoas não viram obra nenhuma, totalmente desacreditada" (SETOR 11). Ressaltamos que antes dessa questão de materialização das demandas do OP, a distribuição de recursos com base em indicadores de carência de infraestrutura no OP (Pires, 2011), tendo como característica por uma tentativa de reversão das prioridades, através de uma fórmula técnica que privilegia os setores mais carentes da população (Avritzer, 2003) também poderá ser motivo de conflito e mediação por parte daqueles envolvidos no processo.

\section{Considerações Finais}

Em 2017, como início de uma nova gestão municipal (2017-2020) da PMVR, que se propusera a colocar em prática as promessas de campanha, então surgiu o 'Governo que Cumpre' e através da SEPLAG buscou um conjunto de ações voltadas à reestruturação de mecanismos de controle social e transparência no município, colocando em prática o Programa VR + Moderna, Transparente e Participativa, sendo que uma dessas ações estava direcionada ao OP, que tinha o deságio de resgatar a confiança dos munícipes, bem como, entregar o controle desse nas mãos da população (SEPLAG-VR, 2018).

Ocorreu uma reestruturação de toda a metodologia do OP-VR, inclusive foi implementado o Orçamento Participativo Digital, que fazia parte da priorização dada pela gestão quanto as ferramentas de governança digital e transparência e controle social, inclusive consta reportagem de uma jornal online que essa metodologia foi reconhecida pelo Observatório Internacional de Democracia Participativa (OIDP), sendo citado tanto pela página, quanto pelo website dessa rede, por ter ficado entre os dez finalistas para receber o 'Prêmio de Boas Práticas em Participação', organizado por essa própria rede e obteve votos de governos de diferentes localidade do mundo. A questão da governança pública para Baptista (2017), compõe mecanismo de desenvolvimento de políticas públicas que interessem diferentes atores e movimentam distintos recursos, tendo em vista a necessidade de articulação entre temas, atores, processos e projetos.

A partir da Técnica de Triangulação proposta por Triviños (1987), ao qual nos ajudou a compreender amplitude do objetivo de estudo, de forma que pudéssemos salientar os Processos e Produtos e averiguar as percepções do sujeito, através das entrevistas (questionários) e observação direta; como também os Elementos Produzidos pelo Meio, ou seja, documentos, instrumentos legais e oficiais do OP-VR. Também a partir de uma base teórica sobre o tema e coleta de dados, estabelecemos as categorias, de forma a agrupar ações, aspectos, elementos e ideias, de modo que servissem para explicar, justificar e questionar a realidade do objeto estudado (Gomes, 2002).

Com relação a primeira categoria Participação, foram constatadas algumas peculiaridades a partir dos relatos de entrevistados e análises das Atas do COP-VR, primeira em relação à metodologia, já que com a reestruturação do OP-VR e a 
implementação do OPD-VR, inicialmente, fez com que houvesse uma dificuldade de entendimento e aceitação por parte de algumas representações das associações de moradores, posteriormente, com a introdução do modelo híbrido, que foi uma estratégia encontrada pelo núcleo de reestruturação do OP-VR para mitigar as resistências ao modelo virtual por parte de algumas associações de moradores, havia relatos dos entrevistados que essas persistiram e evidenciavam como a questão de 'perda de poder'.

No que tange à segunda categoria Representação, ficou evidenciado que a política tradicional no OP-VR mostrou-se muito presente de forma a manter-se no poder, de certa forma, mantendo uma cultura clientelista e patrimonialista, tal como: caráter fechado de algumas associações; benefícios através de uma relação exclusiva entre líderes comunitários e seus chefes políticos; interação entre alguns membros da Administração Pública, cidadãos e o Legislativo permeada um pouco pela cultura de favor e questão de poder enquanto hierarquia.

Já ao analisarmos a terceira categoria Controle Social e Transparência, pudemos destacar algumas dificuldades que fizeram parte do escopo daquelas enfrentadas pelo OP-VR, como as questões de multiplicação de conhecimento, já que a capacitação esteve concentrada na representação da sociedade civil e alguns grupos centralizavam esse conhecimento e não davam as devolutivas as suas bases. Nesse sentido, havia uma dificuldade de se criar um círculo virtuoso de controle social efetivo.

Em nossa última categoria de análise, a Distribuição de Recursos, teve o intuito de observar se as demandas do OPVR foram priorizadas dentro da burocracia municipal, sabendo-se que num ciclo do orçamento participativo são várias etapas a serem cumpridas até se chegar as demandas aprovadas e para que essas sejam executadas, há um outro trâmite processual e legal para que possa produzir resultados.

Diante disso, ao analisarmos essa reestruturação do OP-VR e o OPD-VR no campo prático, concluímos que os mecanismos participativos e deliberativos de questões públicas com participação em minoria nos espaços de deliberação institucionalizados. Além disso, ao implantar uma ferramenta digital, reconhecendo as limitações como a exclusão digital, podemos inferir a lógica mercadológica presente, pois nem todos estariam aptos a participar. Cabe destacar ainda que, mecanismos de participação digital que priorizam ações individuais, não oferecendo espaços de deliberação coletiva, de certa forma, diminuem a importância coletiva da participação.

Por fim, alguns elementos são necessários de destaque em termos de estudos futuros. São necessárias pesquisas empíricas que analisem o impacto da infraestrutura na capacidade de participação (seja na qualidade quanto na quantidade em contextos de plena ou de falta de infraestrutura) - nosso estudo observou, empiricamente alguns pontos, contudo, falta abordagem localizada de estudo de caso. Em seguida, um estudo acerca da qualidade da transparência de dados é fundamental, tendo em vista que evidenciamos, por meio da presente pesquisa, que a dificuldade no acesso aos dados sobre orçamento participativo encontra resistência. Uma outra sugestão que verificamos como pertinente, está em observar as dinâmicas e impactos associados à multiplicação de conhecimento dentre os participantes do processo de orçamento participativo (em especial, na sua versão digital), considerando a possibilidade de ampliação do uso deste instrumento.

\section{Referências}

Abers, R. N. (1998). Do Clientelismo à Cooperação: governos locais, políticas participativas e organização da sociedade civil em Porto Alegre. Cadernos IPPUR, 12(1), 47-78.

Abreu, J. C. A. de. (2012). Participação Democrática na Administração Pública mediada pela Internet: o caso do Orçamento Participativo Digital. 257 f. Tese (doutorado). Universidade Federal da Bahia, Escola de Administração, Salvador.

Abreu, J. C. A. de., \& Pinho, J. A. G. de. (2014). Sentidos e significados da participação democrática através da Internet: uma análise da experiência do Orçamento Participativo Digital. Rev. Adm. Pública, 48(4), p. 821-846.

Arretche, M. (2015). Trazendo o conceito de cidadania de volta: a propósito das desigualdades territoriais. In: Arretche, M. (org.). Trajetórias das desigualdades: como o Brasil mudou nos últimos cinquenta anos. (1ª.ed.) São Paulo: Unesp, 193-222. 
Avritzer, L. (2003). Modelos de deliberação democrática: uma análise do orçamento participativo no Brasil. In: Santos, B. de S. (Org.). Democratizar a democracia: os caminhos da democracia participativa. Rio de Janeiro: Civilização Brasileira, 561-598.

Baptista, V. F. (2020). The critique of justice in the debate between Nancy Fraser and Axel Honneth: notes toward a critical theory. Revista Argentina de Ciencia Política, 1, 37-62.

Baptista, V. F. (2019). Tecnologia e desenvolvimento social: Uma abordagem teórica. Perspectivas Em Gestão \& Conhecimento, 9, 4-23.

Baptista, V. F. (2017). A governança pública como antigovernança. Revista Eletrônica Espaço Acadêmico (Online), $17,122-134$.

Bordenave, J. E. D. (1994). O que é participação. São Paulo: Brasiliense.

Brito, T. M. de., Santos, A. T. de O., Dias, C. A., \& Santos, C. M. (2020). Garantia dos direitos fundamentais através das funções estatais na execução do orçamento público: uma revisão integrativa da produção científica dos últimos dez anos. Research, Society and Development, 9(5), 1-18.

Bugarin, M. S., Vieira, L. M., \& Garcia, L. M. (2003). Controle dos gastos públicos no Brasil: instituições oficiais, controle social e um mecanismo para ampliar o desenvolvimento da sociedade. Rio de Janeiro: Konrad-Adeunauer Stifung.

Campos, G. A. de. (2011). Participação e Representações não avaliativas: a produção de significados nas experiências participativas. In: Pires, R. (org.). A efetividade das instituições participativas no Brasil: estratégias de avaliação. Brasília: Ipea, 53-64.

Cunha, M. A. V. C. da., Coelho, T. R., \& Pozzebon, M. (2014). Internet e Participação: o caso do Orçamento Participativo Digital de Belo Horizonte. Rev. adm. empres., 54(3), 296-308.

Demo, P. (2009). Participação é conquista: noções de política social participativa. (6ª.ed.) São Paulo, Cortez.

Faria, C. F. (2016). Democracia deliberativa e (des) igualdade. In: Miguel, L. F. (org.). Desigualdades e democracia: o debate da teoria política. São Paulo: Unesp, 203-222.

Faria, C. F., \& Ribeiro, U. C. (2011). Desenho institucional: variáveis relevantes e seus efeitos sobre o processo participativo. In: Pires, R. (org.). A efetividade das instituições participativas no Brasil: estratégias de avaliação. Brasília: Ipea, 125-135.

Ferreira, D. E. S. (2012). Uma análise comparada do impacto dos usos das novas tecnologias digitais na dinâmica participativa e deliberativa dos orçamentos participativos de Belo Horizonte e Recife. Tese (Doutorado em Ciência Política), Universidade Federal de Minas Gerais, Belo Horizonte, 2012.

Ferreira, D. E. S. (2014). Participação e Deliberação: análise do impacto dos usos das Novas Tecnologias Digitais na dinâmica dos Orçamentos Participativo de Belo Horizonte e Recife. In: Silveira, S. A. da., Braga, S., Penteado, C. (Orgs.). Cultura, Política e Ativismo nas Redes Digitais. Fundação Perseu Abramo: São Paulo, 189-214.

Gomes, R. (2002). A análise de dados em pesquisa qualitativa. In: Minayo, M. C. de S. (Org.). Pesquisa Social - Teoria, Método e Criatividade. (21 ${ }^{\mathrm{a}}$ Ed.) Vozes: Petrópolis, 67-80.

Habermas, J. (1996). Between facts and norms: Contributions to a discourse theory of law and democracy. Cambridge: Polity Press.

Habermas, J. (2014). Mudança estrutural na esfera pública. São Paulo: Edunesp.

Lavalle, A. G. (2011). Participação: valor, utilidade, efeitos e causa. In: Pires, R. (org.). A efetividade das instituições participativas no Brasil: estratégias de avaliação. Brasília: Ipea, 33-42

Lüchmann, L. H. H. (2014). 25 anos de Orçamento Participativo: algumas reflexões analíticas. Política \& Sociedade, 13(28), 167-197.

Luciano, E. C. S., \& Baptista, V. F. (2020). Conselho Municipal de Desenvolvimento rural Sustentável de Volta Redonda: a norma e o real. Revista Brasileira de Assuntos Regionais e urbanos (BARU), 6, 1-23.

Marques, F. P. J. A. (2010). Participação política e desenho institucional: uma proposta para a concepção de mecanismos participativos. Ciências Sociais Unisinos 46(2), 140-151.

Marquetti, A., Campos, G. A., \& Pires, R. R. (orgs.). Democracia participativa e redistribuição: análise de experiências de orçamento participativo. São Paulo: Xamã.

Miguel, L. F. (2016). O liberalismo e o desafio das desigualdades. In: Miguel, L. F. (org.). Desigualdades e democracia: o debate da teoria política. São Paulo: Editora Unesp, 25-66.

Miguel, L. F. (2017). Resgatar a participação: democracia participativa e representação política no debate contemporâneo. Lua Nova, $100,83-118$.

Minayo, M. C. de S. (Org.) (2002). Pesquisa social: teoria, método e criatividade. (21ª. Ed.) Petrópolis: Vozes.

Miola, E. (2009). A Deliberação Online em Ambientes Institucionais: um estudo do Fórum de Discussão do Portal da Câmara dos Deputados. Contemporânea, $7(2), 1-24$.

Nabuco, A. L., Macedo, A. L., \& Ferreira, R. N. (2009). A Experiência do Orçamento Participativo Digital em Belo Horizonte: O Uso das Novas Tecnologias no Fortalecimento da Democracia Participativa. Informática Pública. 11(1), 139-155.

Offe, C. (1984). Problemas Estruturais do Estado Capitalista. Rio de Janeiro: Tempo brasileiro. 
Research, Society and Development, v. 10, n. 14, e543101422491, 2021

(CC BY 4.0) | ISSN 2525-3409 | DOI: http://dx.doi.org/10.33448/rsd-v10i14.22491

Paes De Paula, A. P. (2005). Administração pública brasileira: Entre o gerencialismo e a gestão social. RAE-Revista de Administração de Empresas, 45(1), 3649.

Paludo, A. V. (2010). Orçamento público e administração financeira e orçamentária. Rio de Janeiro: Elsevier.

Pateman, C. (1992). Participação e Teoria democrática. Rio de Janeiro: Paz e Terra.

Pitkin, H. F. (2006). Representação: palavras, instituições e ideias. Lua Nova, 67, 15-47.

PMVR (Prefeitura Municipal de Volta Redonda). Atas do Comitê do Orçamento Participativo de Volta Redonda (2018/2020) - Prefeitura Municipal de Volta Redonda. https://sites.google.com/view/orcamentoparticipativo/atas-das-reuni\%C3\%B5es.

Sampaio, R. C. (2014). Orçamentos participativos digitais: um mapeamento mundial das experiências já realizadas e suas contribuições para e- participação e e-democracia. 363 f. Tese (Doutorado) - Programa de Pós-Graduação em Comunicação e Cultura Contemporâneas, Universidade Federal da Bahia, Salvador.

Sampaio, R. C., Maia, R. C. M., \& Marques, F. P. J. A. (2010). Participação e deliberação na internet: Um estudo de caso do Orçamento Participativo de Belo Horizonte. Opinião Pública, 16(2), 446-477.

Santos, B. de S (Org.). (2002). Democratizar a democracia: os caminhos da democracia participativa. Rio de Janeiro: Civilização Brasileira.

Santos, B. de S., \& Avritzer, L. (2002). Introdução: para ampliar o cânone democrático. In: Santos, B. de S. (org.). Democratizar a democracia: os caminhos da democracia. Rio de Janeiro: Civilização Brasileira, 39-42

Seplag-VR (Secretaria Municipal de Planejamento, Transparência E Modernização da Gestão da Prefeitura de Volta Redonda). Prêmio Melhores Práticas, 2018. Tribunal de Contas do Estado do Rio de Janeiro: Rio de Janeiro, 2018. https://www.tce.rj.gov.br/documents/454798/82709826/Relato\%206.pdf.

Silva, M. K. (2011). Dos casos aos tipos: notas para uma apreensão das variações qualitativas na avaliação das instituições participativas. In: Pires, R. (org.). A efetividade das instituições participativas no Brasil: estratégias de avaliação. Brasília: Ipea, 233-246.

Teixeira, R. R., Dias, C. A., Santos, C. M., \& Barros, G. F. (2021). Instrumentos de caráter jurídico e técnico de suporte à adoção do programa de despesas públicas e responsabilidade financeira (PEFA) na avaliação da gestão das finanças públicas municipal. Research, Society and Development, 10(4), 1-12.

Triviños, A. N. S. (1987). Introdução à pesquisa em ciências sociais: a pesquisa qualitativa em educação. São Paulo: Atlas.

Wampler, B. (2003). Orçamento Participativo: uma explicação para as amplas variações nos resultados. In: Avritzer, L., Navarro, Z. (Org.). A inovação democrática no Brasil: o orçamento participativo. São Paulo: Cortez.

Vaz, A. C. (2011). Da Participação à qualidade da deliberação em fóruns públicos: o itinerário da literatura sobre Conselhos no Brasil. In: Pires, R. (org.). A efetividade das instituições participativas no Brasil: estratégias de avaliação. Brasília: Ipea, 91-107 